\title{
Challenges Associated with Creeping Disasters in Disaster Risk Science and Practice: Considering Disaster Onset Dynamics
}

\author{
Reidar Staupe-Delgado ${ }^{1,2} \cdot$ Olivier Rubin ${ }^{1}$
}

Accepted: 23 December 2021/Published online: 12 January 2022

(C) The Author(s) 2022

\begin{abstract}
In this article, we set out to reconcile a general conceptualization of disaster temporalities by drawing on the epitome example of a creeping disaster, namely famine. Our argument is driven by the recognition that slowly manifesting disaster impacts pose distinct challenges for decision makers and researchers while there is a tendency for the disaster literature to overlook the role of disaster onset dynamics. More specifically and as a starting point, we identify four key themes that merit particular attention when dealing with creeping disasters: (1) our understanding of disaster as a phenomenon; (2) measurement and operationalization; (3) early warning and response; and (4) disaster management and termination. By integrating conceptual discussions of disaster with famine scholarship-a phenomenon often excluded from mainstream disaster research-this article provides fresh perspectives on disaster science as well as a number of implications for how we think about disaster risk reduction.
\end{abstract}

Keywords Disaster response - Early warning - Famine disasters $\cdot$ Slow-onset disasters

Reidar Staupe-Delgado

staupedelgado@gmail.com

1 Department of Social Sciences and Business, Roskilde University, 4000 Roskilde, Denmark

2 Department of Technology and Safety, UiT The Arctic University of Norway, 9037 Troms $\varnothing$, Norway

\section{Introduction}

Disasters differ considerably in manifestation speed and pattern, which in turn affects the way in which researchers and decision makers understand and respond to them (OCHA 2011; Matthewman 2015; Staupe-Delgado 2019a; Boin et al. 2020). Some disaster impacts, such as those associated with earthquake hazards or common industrial accidents, manifest themselves abruptly. Other types of disaster impacts are more creeping in the sense that they affect societies more gradually and elusively with geographical scopes that are hard to define. The question of creeping disaster as an overall phenomenon has tended to be overlooked both theoretically and empirically within the field of disaster studies (Quarantelli 1998; Rosenthal 1998; Dynes 2004; Hsu 2019). While slow-onset phenomena have not been ignored per se, these literatures have remained poorly integrated into mainstream disaster theories. A few recent contributions have attempted to remedy this state of affairs but have tended to focus on concept formation (Hsu 2019; Staupe-Delgado 2019a; Boin et al. 2020; Yamori and Goltz 2021), methodological aspects (Meriläinen and Koro 2021), or diplomacy (Kelman et al. 2018). Distinctions between rapid-onset and slow-onset disasters have been discouraged in the field on the grounds that all disasters are conceptually understood as inherently slow processes to begin with due to the fact that they all originate from prefigured patterns of vulnerability (Lewis 1988; Wisner et al. 2004; Meriläinen and Koro 2021). This leads to the natural conclusion that hazards may have slow or rapid onsets, but all disasters are gradually occurring, meaning that none are rapidly occurring.

At the same time, we intuitively know that the way in which adversities become manifest matters for how they are suffered, and conditions how we can deal with their 
immediate (as well as oftentimes gradually worsening) consequences. This is not to negate the role of vulnerabilities and the importance of addressing these. Following the reasoning of Quarantelli (1997), regardless of the hazards, most disasters generate similar demands and give rise to a need for similar functions (for example, evacuation, search and rescue, and tending to the wounded). The concept of disaster is recognized as highly multifaceted, encompassing root-cause perspectives alongside long-term societal repercussions. This article centers on the notion of disaster impacts, which we take to be the adverse effects of an insufficiently mitigated hazard that interacts with a vulnerable or exposed population.

We thus set out to reconcile disaster risk science with the long history of scholarship on the epitome of creeping disasters-namely famine disasters. The article is inspired by our observation that famines are largely absent from mainstream disaster scholarship, although a number of important disaster science contributions are based on famines (Glantz 1976; De Waal 1989; Keen 1993; for an overview see Staupe-Delgado 2019a). Famines arguably challenge the stereotypical hazard/disaster distinctionthey are the result of numerous compounding factors while in themselves constituting disasters; famines are often a disaster in a disaster. At the same time, like other disasters, famines are also undeniably one of the best examples of a disaster that is attributable to vulnerabilities as the very condition of famine is typically the conclusion of prolonged periods of turmoil, poorly mitigated natural hazards, and socioeconomic inequalities and abuse (Hewitt 1995).

We engage recent scholarship in the field and argue for increased attention to temporalities in the wider debate surrounding the "what is a disaster?" question (Quarantelli 1998; Perry and Quarantelli 2005). This conceptual exercise allowed us to identify a set of traits or distinct challenges posed by creeping disasters, which we have organized into four overarching themes:

(1) The disaster concept-our understanding of disaster as a phenomenon;

(2) Measurement and operationalization-identifying emerging creeping disasters;

(3) Early warning and response-barriers for translating detection into timely response;

(4) Disaster management and termination-distinct disaster management challenges.

These four themes are inextricably linked. However, famine research suggests that distinct characteristics and dynamics are associated with each of the themes.

The next section elaborates on the concept of creeping disasters from the perspective of disaster risk science, with particular focus on the notion of onset dynamics and impact manifestation patterns. The third section outlines the nature of famine disasters. The fourth section discusses the distinguishing features of creeping disasters with respect to the four themes, including reflections on the practical significance for comprehension, prediction, response, and management, with the aim of demonstrating that creeping disasters pose a set of distinct challenges for disaster management. The concluding section summarizes the salient points raised in this article as well as their implications for famine research and disaster scholarship.

\section{Creeping and Gradually Manifesting Disasters}

The concept of disaster is typically understood in terms of a disruptive departure from what may be labelled normal conditions (Quarantelli 2000; Tierney and Bruneau 2007). Other conceptualizations of disaster have underlined precisely this role of seemingly "normal" conditions in prefiguring or constructing disaster risk (Hewitt 1983; Kelman 2020). In reality, a neat dichotomy between normality and disaster, or other "phases" of disaster, does not exist (Neal 1997; Coetzee and Van Niekerk 2012; Bosher et al. 2021). While disaster impacts are increasingly seen as processes rather than one-off events, disasters are typically imagined in the form of graphic images of material destruction, a need for getting out of harm's way and as "events" followed by recovery in their aftermath. In this way, disasters are classically understood as a radical rupture from the status quo, triggering sentiments of disbelief and time compression-which in turn generates an intense urgency to act. The "disaster occurrence" itself is commonly understood in "sudden-onset" terms (although disasters often have lasting consequences), seen as implying impact trajectories that consist of abrupt, unexpected devastation followed by a race to recover back to how things were (Meriläinen and Koro 2021). This is also implied by the urge to build back better, recover resiliently, or other temporal foci that cast disasters as "events" (Bosher et al. 2021). The following definitions, for example, conceptualize "disaster" as:

An event, concentrated in time and space, in which a society or a relatively self-sufficient subdivision of a society undergoes severe danger and incurs such losses to its members and physical appurtenances that the social structure is disrupted and the fulfilment of all or some of essential functions of the society is prevented (Fritz 1961, p. 655).

Relatively sudden occasions where because of perceived threats the routines of the collective social units involved are seriously disrupted and where 
unplanned courses of action have to be undertaken to cope with the crisis (Quarantelli 1991, p. 2).

A sudden, calamitous event that seriously disrupts the functioning of a community or society and causes human, material, and economic or environmental losses that exceed the community's or society's ability to cope using its own resources. Though often caused by nature, disasters can have human origins (IFRC 2020).

A serious disruption of the functioning of a community or a society at any scale due to hazardous event interacting with conditions of exposure, vulnerability, and capacity, leading to one or more of the following: human, material, economic and environmental losses and impacts (UNDRR 2017).

It is clear that these definitions do not facilitate discussions of creeping phenomena as disastrous. Two highly influential definitions from the disaster studies literature (Fritz 1961 and Quarantelli 1991) seek to limit the field to encompass only abrupt adversities. The International Federation of Red Cross and Red Crescent Societies (IFRC) defines disaster in terms of sudden, calamitous events in the context of their work and mandate. As such, disaster scholarship remains heavily focused on models that implicitly theorize on the basis of "conventional disasters" that are assumed to be divisible into sequence patterns.

One such reason is perhaps an early observation that "all disasters are slow onset when realistically and locally related to conditions of susceptibility" (Lewis 1988, p. 4). Newer definitions have underlined the role of overrun local capacities and demand surges that give rise to a need for outside assistance to cope (Kelman 2020). It is true that all disasters have the potential of becoming protracted processes where, particularly the most vulnerable, may well never fully recover in their wake. It is also true that all disasters can be traced back to decades or centuries long precursory processes of vulnerability creation and neglect as the ultimate root cause of disastrous outcomes. Considering the speed at which disaster impacts become manifest is not the same as ignoring the role of vulnerabilities, however.

One should be careful not to confound these kinds of causal theories and more practical analyses connected to disaster management and lived experience. The difference lies mainly in what is anticipated-people exposed to creeping disasters experience gradually worsening conditions with perhaps no clear end in sight. During famines, for example, one can observe the seemingly paradoxical behavior where households choose not to eat their available food (De Waal 1989; Keen 1993; Osmani 1993). By slaughtering their livestock, households increase their chance of short-term survival, but in doing so they become vulnerable for many years to come. Instead, people exposed to famine preserve their livestock and use seeds to plant their fields (instead of for consumption) in anticipation of better times that might never materialize. Because conditions continue to worsen with no apparent end in sight, affected populations will often live in uncertainty as to whether better times are just around the corner or whether the worst is yet to come. These types of coping strategies demonstrate how more creeping onset speeds are associated with intense uncertainty and an experience of living in anticipation of a highly uncertain future as affected populations cannot know in the present if the situation will improve in some months or whether recovery will be much more elusive.

We posit that gradually manifesting forms of destruction and adversity might pose challenges that differ from those of more immediate forms of destruction (Twigg 2004). In his seminal work on creeping environmental problems, Glantz (1994) noted that one central challenge is their gradual onsets and dispersed impacts that reduce their salience among decision makers: "a change in this type of environmental problem is not much worse today than it was yesterday; nor is the rate or degree of change tomorrow likely to be much different than it is today" (Glantz 1994, p. 3). Elusive hazards often lead to diffuse disasters-disasters that often require data on specific parameters to even determine that they are in motion (Kelman 2019). They often give rise to certain adjustments when conditions allow, but also shape vulnerabilities (Burton et al. 1993). While they share a number of commonalities with disaster as a general phenomenon, they could be distinct in the sense that their ambiguous existence renders them easily ignorable and difficult to observe in the absence of deliberate monitoring.

These differences, we would underline, do not necessitate major qualitative shifts in our understanding of disasters but demonstrate that systems developed for more acute types of occurrences will be less relevant in the context of creeping disasters. Studying creeping disasters as an overall category, therefore, assumes that certain onset-related impact dynamics shape response and planning challenges. Investigating creeping phenomena comparatively would leave us better positioned to analyze the role that onset dynamics play in how we think about disasters and how we work to mitigate their impacts and respond to them (Staupe-Delgado 2019b). Creeping disasters display certain spatiotemporal characteristics that are less evident in the context of more immediately felt disasters, such as the challenge of noticing its existence and securing proactive response before it is too late. For many elusive and gradually occurring kinds of disaster impacts the very existence 
of an onset is oftentimes controversial, at least for some time before evidence becomes irrefutable.

The call for excluding creeping or "slow-onset" disasters from disaster studies can be traced back to one of the most influential pioneers of modern disaster sociology, E.L. Quarantelli. Famously, he expressed apprehension against including chronic, diffuse, and long-term situations such as famines, epidemics, and droughts (FEDs) in the category of disasters, stating in the Epilogue of the prominent scholarly work, What is a Disaster?, that his inclination "would be to exclude FEDs from the disaster category and to treat FEDs as social problems, involving chronic stress settings rather than crisis occasions" (1998, p. 260). Quarantelli put forward two arguments in support of this position (Quarantelli 1998; Hannigan 2013).

First, Quarantelli (1998) explained that slow-onset situations lack the disruptive effects we commonly associate with disasters that are relatively more focused in time and space. Such a descriptive and definitional statement in and of itself hardly constitutes a robust case for exclusion from the field. There is such great heterogeneity in the core characteristics of disasters already included in disaster research that the described temporal variations in disaster impacts appear inadequate to make an argument against inclusion.

His second objection appears more convincing, that there is minimal overlap between the empirical data and theoretical ideas on creeping disasters and those relating to more rapidly manifesting disaster impacts. Quarantelli (1998, p. 266) argued that "many well-established observations findings about disaster behavior at any level of analysis, simply do not appear to apply to these diffuse kinds of happenings." Such an argument could strictly be taken to mean that the paradigms are incommensurable in a Kuhnian sense or merely that there is little to be gained from addressing creeping (ongoing) phenomena from a disaster perspective. The argument of limited overlap, by Quarantelli's own admission (1998), relies on very informal and unsystematic observations. Interestingly, he only contemplated the scope for applying literatures relating to creeping disasters to more conventional disasters and not cross-fertilization the other way around (that is, applying disaster research concepts and perspective to the study of famine). In this article we put forth the argument that recent conceptual developments appear to increase the opportunity and value of addressing famines from a disaster perspective and advance an ongoing agenda of conceptualizing the onset aspect of disasters more explicitly (Glantz 1994; Matthewman 2015; Hsu 2019; Staupe-Delgado 2019a). Famine understandings have moved from primarily a developmental process perspective to an "event-based" perspective where political accountability (and criminalization) is emphasized.

\section{Famine as One Type of Creeping Disaster}

Most disaster research that contributes to our understanding of slowly manifesting disaster impacts has focused on the impacts of droughts and gradual processes of environmental change (Staupe-Delgado 2019a). Drought, importantly, is not synonymous with famine. While drought is a natural hazard, famine is the archetypical creeping disaster. Drought is a recurring feature of the climate in most parts of the world and occurs for a variety of reasons, not all meteorological (Wilhite and Glantz 1985), and droughts very rarely trigger famines. Famines are also not intrinsically linked to droughts. The 1974 Bangladesh famine, for example, that claimed the lives of a least 300,000 people was not preceded by widespread droughts but rather by prolonged floods, which submerged large parts of the country (Dowlah 2006). Drought is neither a necessary nor a sufficient condition for famine. As with all disasters, famines too arise from vulnerabilities. In fact, contemporary famine has become increasingly disassociated from natural hazards such as droughts. Famines have become much more closely associated with civil war, extreme destitution, and political unrest (De Waal 2018; Rubin 2019).

If we consider famines as a creeping form of disaster, famines should not be perceived as the final cataclysmic outcome of a linear trajectory characterized by continued deterioration of a country's nutritional status. Rather, famines are usually much messier with a large element of nonlinear sociopolitical dynamics with multiple pathways in which vulnerable populations can fall into famine (Patnaik 1991; Rubin 2009a; De Waal 2018; Howe 2018; Maxwell et al. 2020). Thus, a longer temporal perspective that encompasses famine as a synergistic outcome of complex indirect and nonlinear sociopolitical dynamics should be preferred. The burden of this creeping disaster can rival many of the other kinds of disasters faced by humans over the centuries. Approximately a quarter million people perished in the 2011 Somalia famine, and currently the number of people estimated to be vulnerable to famine has almost doubled from 27 million in 2019 to 45 million in 2021 (WFP 2021). Famines are among the few disasters to spare most types of physical capital (roads, bridges, houses, and so forth). In that sense, famine has much in common with other creeping phenomena, namely pandemics and antimicrobial resistance (Viens and Littmann 2015). Scorched agricultural fields are not a prerequisite for famine. Instead, it often coincides with and is concealed by the chaos of conflict and general misery and can occur in one segment of the population without afflicting the entire population. 
A famine is clearly not a hazard as typically understood in disaster risk science. Famines also fit poorly with prevailing (sudden-onset based) disaster definitions. However, this does not in itself position us to conclude that it is productive to frame famine situations as creeping disasters. One of Quarantelli's (1998) chief objections for their inclusion in disaster risk research was the theoretical and empirical disconnect between these types of gradually manifesting and diffuse processes of harm and more instantaneously felt disaster impacts. There need to be analytical advantages to approaching a societal phenomenon as a creeping kind of disaster instead of as a principally development, economic, health, or political problem or failure. Defining famine disasters as creeping disasters without addressing the "so what?" question would be unsatisfactory. The very discussion of disaster temporalities has remained controversial and advancing thought on the matter would in itself contribute to expanding and adding nuance to the term. Moreover, identifying disaster management implications would suggest the discussion has practical implications. The next section will discuss some of the distinguishing features of creeping disasters, of which famine may be considered one example, and outline the analytical advantages of explicitly acknowledging these features in light of our four themes.

\section{4 (Re)considering Creeping Disasters: Four Sets of Insights Based on Famine Onset Dynamics}

Creeping disasters demonstrate a set of distinguishing features with implications both for how we think about disaster impacts and onset dynamics, including practical implications. These features help us conceptualize how creeping disasters are distinct in terms of lead time, as in theory, their impacts could be easier to brace for proactively than in cases where destruction is more temporally concentrated. Yet the slowness of their manifestation may itself prove a barrier to effective response due to a perceived lack of acuteness-famine disasters serving as our case in point. We have structured our reflections according to four related themes: (1) the disaster concept; (2) measurement and operationalization; (3) early warning and response; and (4) disaster management and termination.

\subsection{The Disaster Concept}

The failure to recognize creeping disaster impacts as a somewhat distinct type of societal problem has led to an undertheorization and underappreciation of their particular disaster risk science challenges. Creeping types of disaster impacts have thus been understudied using the tools and approaches that stem from disaster risk science, the principal among these being the interdisciplinary modus operandi that permeates the field. Ironically, creeping disasters, with their ambiguity and slow onsets, may be the phenomena most in need of this kind of interdisciplinary treatment, which this field can offer.

Sen (1981) effectively dislodged the understanding of famine from that of drought by stressing how the cause of famine was not a lack of food (production failure) but rather a lack of access to food (market failure). Thus, contemporary definitions of famine make no mention of a particular hazard (such as droughts, floods, or locust swarms). Rather, famines are often defined generically as an idiosyncratic event identifiable by excess mortality caused by mass starvation (Sen 1981; Howe and Devereux 2004; Gráda 2009; Rubin 2009b). Despite this understanding of famine as an idiosyncratic event, contemporary famines have mainly been addressed as a developmental challenge (Devereux 2007; De Waal 2018; Rubin 2019). Initially, Sen avoided the disaster term altogether in his major work on famine, except in a brief reference to famines as "economic disasters" (Sen 1981, p. 161). However, in the 1990s several famine scholars, including Sen, began using the term "disaster" more frequently.

In his other major work on famine (where he applied a more political perspective to the analysis of famine), Sen explicitly referred to famines as disasters, arguing that "there is need for economic and political analyses here, as there also is for having a fuller understanding of crises and disasters other than famines" (Sen 1999, p. 161). Likewise, Hewitt (1995, p. 115) argued that famine was an "archetypal case of disaster prefigured by 'underdevelopment." "In his influential work on famine crimes, De Waal also used the term "famine" and "disaster" interchangeably throughout the book (De Waal 1997). As opposed to arguing that famines are non-disasters, they have been framed as a particular kind of disaster. Still, Quarantelli described, based on his own experience, how famine scholars were not part of the social circles of disaster researchers in the 1990s (Quarantelli 1998). Not much appears to have changed since then, as recently documented by Rubin (2019), who argues that famines appear mostly restricted to historical and development scholarly circles, and they are noticeably absent at major disaster conferences.

One of the difficulties with approaching famine as an idiosyncratic event (which no disaster is anyway) is that, until recently, the identifying triggers for famine remained elusive. While understandings of famine clearly referred to a sudden and extra-ordinary situation (with other disasters similarly mislabeled), the actual demarcation of famine was difficult to establish in practice. This is along the lines of Quarantelli's (1998) argument that ambiguous disasters, characterized by temporal and spatial diffusion, should be 
considered as something "other" than a disaster. Hence, while definitions of famine were event-focused (much like the misnomer "rapid-onset disasters"), the actual operationalization of famine remained underdeveloped. For the last 15 years, however, key international organizations and international nongovernmental organizations (major UN agencies, CARE international, Oxfam, Save the Children, and others) have worked on a set of standardized tools and measurements for the declaration of famine. These guidelines have most recently been published in an Integrated Food Security Phase Classification (IPC) table, allowing for a more demarcated identification of famine (IPC 2020). Today, the United Nations classifies famine based on explicit qualitative and quantitative indicators. The three key criteria for declaring famine in an area are whether indicators are currently above or projected to be above the following thresholds: (1) more than $20 \%$ of households experiencing extreme food gaps; (2) more than $30 \%$ of children acutely malnourished; and (3) crude mortality rates exceeding $2 / 10,000 /$ day. This explicit operationalization has allowed for famines to be approached much more as identifiable events-with all the shortcomings that such a technocratic perspective entails.

This event-focused understanding and operationalization is not much different from the disaster definitions listed previously. These famine benchmarks have been used to declare famines on two occasions: on 20 July 2011 in parts of Somalia, and on 20 February 2017 in South Sudan. According to the IPC (2021), the present 2021 humanitarian catastrophe in Ethiopia does not (yet) live up to a famine disaster classification despite widespread malnutrition rates.

Another recent relevant development in famine research is the greater appreciation for and formalization of political dynamics that mirrors that of disaster research. One of the most influential famine scholars, Stephen Devereux (2007), has identified a recent shift in the understanding of famine from one emphasizing market-based failures to one looking at them as failures of political accountability and response (transfer-based failures). The subject of practical and scholarly interest is not the socioeconomic "shocks" themselves but the failure to respond to such "shocks." This is very much in line with disaster research where most disaster scholars and practitioners show evidence that prevention, preparedness, and response are determined by political factors. Following this understanding, the criminalization of famine has been revitalized. Although the discussions of famine as a criminal act was spearheaded by anthropologists in the 1990s, most notably De Waal (1993) and Keen (1994), it was more than a decade before this perspective was picked up by legal scholars (Marcus 2003; DeFalco 2017; Conley and De Waal 2019). In his most recent monograph on famine, De Waal (2018) explicitly emphasized the need for distinguishing famine from (chronic) hunger and malnutrition, arguing instead for a closer association with mass atrocities. These calls for famine criminalization, published mostly in international law and justice outlets, resonate in key international organizations with their investigations of non-violent human rights violations and the establishment in 2000 of a Special Rapporteur on the right to food (OHCHR 2021).

The event-focused approach to famine, together with the attention to complex political dynamics, we argue, has increased the opportunities and rewards for integrating these types of more creeping situations in disaster research. Rather than seeing slow-onset and rapid-onset disasters as two distinct categories (or as incompatible with each other), there is merit in conceptualizing them along a temporal continuum where certain dynamics are more or less pronounced with slower disaster impact manifestations. Treating famine as a disaster would allow for insights from a disaster research domain that has expertise with crisis management, strong links to policy making, and rich theoretical developments.

This "disasterization," as it were, of adverse occurrences like famine, should not be conflated with merely applying a different framing or rendering famines more salient (political strategic use of the disaster term); rather, it entails addressing the phenomenon from an analytically productive vantage point that we argue disaster studies can offer as a field. Although attempts have been made within the current conceptual paradigm to apply a disaster studies lens to concepts like pandemics and industrial explosions, it appears clear that the conceptual apparatus largely centers on the impacts of natural hazards, such as floods, earthquakes, hurricanes, and tsunamis. It is not that other hazards have not been studied (ample contributions suggest otherwise), but rather that the conceptual apparatus and examples often revolve around natural hazards-related disasters. We argue that casting a wider net can enrich disaster risk science, but it also implies a willingness to innovate conceptually and operationally.

\subsection{Measurement and Operationalization}

Slow-onset disaster impacts increase the scope for early action but are limited by detectability and barriers to declaring an emergency before impacts are "sufficiently severe" to demand a response (Glantz 1994). By definition, more creeping disaster impacts build up and evolve over prolonged periods of time, thus providing (in theory) ample opportunities for preventive and mitigative measures to be put into place in their advent. That creeping disaster impacts are suffered gradually means that the initial problem is mainly one of "noticing" (Staupe-Delgado 2022). While creeping disaster impacts are easier to 
prevent in theory, they are also more difficult to warn against at an early stage because there are no clear-cut benchmarks. When does an infectious disease go from being an outbreak, to an epidemic, to a pandemic? This ambiguity is precisely the reason behind the IPC's standardized indicators for famine declarations.

It is hard to establish when a threat moves from disaster risk to disaster fact, which shapes the political salience of such disasters. Identifying the existence of these threats is a first step towards rendering them real in the public imagination and in the eyes of decision makers. Famine forecasts today, for example, rely as much on monitoring socioeconomic factors, such as coping strategies, price fluctuations, and adverse anthropomorphic indicators as they rely on pure hazard monitoring. The challenge for preventive actions is that many of these are trailing indicators-they provide evidence of a disaster in the making in the form of gradually worsening conditions, also opening up discussions centered on identifying thresholds for when conditions that simmer in the background somehow warrant emergency status. A variety of tools are used to render these disasters real, often relying on modeling, statistics, and projections. This holds particularly true for several high-profile contemporary health disasters such pandemics and antibiotic resistance.

One defining feature of creeping disaster impacts is the notable potential for anticipating how they will continue to develop over time owing to their relatively slow buildup. This refers not necessarily to the slow evolution of hazardous conditions that may be driving the disaster forward, but also the slow manifestation of the gradually worsening socioeconomic conditions that produce temporally dispersed disaster impacts (Staupe-Delgado 2022), which means that warning signs must also be looked for in the societal sphere in the form of indicators (Kelman and Glantz 2014). Famines encompass these creeping characteristics that make them amenable to early detection but at the same time susceptible to trailing indicators that impede an early response. A recurrent challenge for famine early warning systems has been distinguishing the onset of famine from a chronic situation of extreme deprivation or food insecurity. There is ambiguity both spatially and temporally, and the benchmarks used for declaring famine are de facto trailing indicators, with high mortality rates being a defining factor.

In spatial terms, Seaman (1993) questioned whether a slight change in mortality in a very large population, resulting in a massive number of starvation deaths, should be categorized as a famine. Similarly, with respect to the temporal dimension Maxwell et al. (2020, p. 2) rightly asked "why is a crisis that kills 4000 people in three months a 'famine' but one that kills 100,000 over the course of a year not a 'famine'?" Matters of operationalization aside, it is clear that determining thresholds remains one obstacle to prevention that is distinct to creeping disaster impacts. The dominant modus operandi of the international community is to intervene only after a situation has deteriorated beyond a certain threshold. The 2021 situation in Ethiopia with an estimated 400,000 acute food insecure people in Tigray, while being characterized as a "catastrophe" and an "emergency," has yet to deteriorate to a state of famine according to the IPC (2021). This reliance on trailing indicators poses a dilemma to creeping forms of disaster, as the response presupposes the identification of an already existing disaster onset.

Most agencies are continually dealing with a multitude of disasters of different magnitudes, which leaves little room for paying attention to seemingly less urgent matters that may or may not flare up at a future time. Gradually occurring disaster impacts may also fall outside the scope of traditional actors and definitions of disaster. These characteristics are consistent with those identified by other researchers, both those who have focused on slowly emerging disasters (Shaluf 2007; Marulanda et al. 2010; Jaime 2013; Matthewman 2015; Zaidi 2018), as well as early warning experts (Ahrens 2003; Alcántara-Ayala and Oliver-Smith 2015; Costella et al. 2017). It therefore seems safe to argue that translating an early warning into a proactive response to creeping disasters demands that resources are spent not only on "extinguishing fires" (responding to current, acute disasters), but also that attention is devoted to longer time frames.

\subsection{Early Warning and Timely Response}

Researchers working on slowly manifesting disasters often observe a tendency for "early warning, late response" (Lautze et al. 2012, p. 43). In the context of famines, this can be ascribed to trailing indicators such as increases in mortality, wasting, stunting, and so on. Still, the detection of slowly menacing disasters may be a necessary condition to effectively address them but it is not sufficient in and of itself. The main challenge for mustering an effective response is that creeping disaster impacts generally do not create much of a stir. It is precisely their quiet and difficultto-perceive manifestation that causes them to be so treacherous, requiring that decision makers realistically observe their potential to continue worsening over time if left unchecked (DeLeo 2016; Staupe-Delgado 2019b). Rather than impacting suddenly in a way that is immediately felt and visible, they are easily ignored, and response is often postponed until more acute impacts surface.

Researchers observe no unambiguous link between disaster severity, either in terms of economic burden or human toll, and political attention or policy change (Birkland 1998; Healy and Malhotra 2009; DeLeo 2016; 
Boin et al. 2017; Rubin 2018). Slowly manifesting disaster impacts are usually associated with lower political salience than impacts that are concentrated in time and space, such as the consequences of an earthquake. Not only are politicians rarely rewarded electorally for a non-disaster (a disaster prevented) but they also need to defend what seem like policy inefficiencies over many years in anticipation of a possible disaster in the future (Rubin 2018). Maintaining expensive dikes in the anticipation of a 50-year flooding event in the face of other more pressing public concerns (such as the quality of elder care, unemployment benefits, and foreign policy challenges) is no easy task for most governments. Essentially, the political price of terminating the creeping disaster will be paid now while the benefits might be reaped in the future, setting up few political advantages to implementing preventive measures despite obvious humanitarian benefits. At the same time, once a sufficient level of acuteness has been reached, interventions may be far costlier and impacts may be difficult to reverse, which would in turn threaten legitimacy in hindsight.

Creeping disasters can potentially be managed and terminated at their early stages, in which case their impacts would largely be avoided. However, it is not uncommon to postpone response initiatives until more reliable data are available, or even until impacts start to become more acute so that an emergency may be declared. During the 2011 Somalia famine, for example, the lack of seeking reliable information on the ground appears to have delayed the humanitarian operation as a whole. Key humanitarian actors were for security reasons placed in Nairobi, which was quite some distance from the impending famine. Thus, they had difficulties distinguishing this famine from many of the other food crises that have faced Somalia on a regular basis (Heaton 2012). Reliable data were not properly sought and the newly developed standardized system for famine declarations was activated too late. However, a belated response could also be the result of the way "disaster phases" are commonly understood, where response follows impacts, and does not precede them. In fact, several countries and international organizations have legal obstacles to proactive release of response funding (StaupeDelgado et al. 2018). These laws often stipulate that the release of funds is contingent on an emergency declaration.

\subsection{Disaster Management and Termination}

Effective response to creeping disaster impacts is also hindered by a series of managerial and practical obstacles that are difficult to overcome due to the very nature of such phenomena. The spatiotemporal fragmentation that often characterizes creeping disasters effectively means that institutional mechanisms designed to deal with more instantaneously felt disasters often become less relevant in this context (Staupe-Delgado 2019b). Many such agencies have mandates that limit the focus of their work to what they claim are spatially and temporally bound disasters, with other agencies in charge of allegedly more elusive and creeping disasters (for example, public health, agriculture, financial mechanisms like insurance or social protection). One contributing factor may be the overreliance on inappropriate frameworks, such as the disaster management cycle.

Contemporary famines, for example, often take place in the midst of institutional collapse, violent internal conflict, and political unrest, or what may be labelled "complex emergencies" (or compound emergencies) (Kruke and Olsen 2012). Fragile institutions and violent conflicts were the primary causes of the 2011 Somalia famine as well as the 2017 South Sudanese famine (Maxwell and Fitzpatrick 2012; Fergusson 2013; De Waal 2018). Yet, due to the recent progress in famine diagnostics, the 2017 South Sudanese famine did not catch the international community off guard. The international early warning systems in place provided timely warnings of the impending disaster (Rubin 2019). But even in the face of these early warning systems, the key humanitarian organizations were slow to mobilize.

\section{Conclusion}

The onset dynamics and manifestation patterns of disaster impacts shape both how people experience disasters as well as how authorities respond to them. Often the disaster field distinguishes between hazards and disasters, arguing that while some hazards may be slow-onset and some rapidonset, all disasters are in fact slow-onset from a causal (vulnerability) perspective. This article sets out to nuance this understanding somewhat, not by critiquing the causal perspective implied, but by thinking about disaster onset speed as distinct from hazard onset speed. This implies that societal adversities can also emerge slowly and elusively, setting such disaster impacts apart from the sets of adversities we more conventionally associate with disastrous conditions.

We argue that paying greater attention to challenges associated with adversities that emerge slowly, such as famines, pandemics, and antimicrobial resistance, would potentially enrich disaster risk science. By studying their commonalities through a concept such as creeping disasters, one could potentially identify shared lessons and understandings that transcend individual types of disasters. The onset dynamics of disaster impacts shape lived experience and disaster management practice. Therefore, it would be a missed opportunity to leave these types of creeping disasters out of disaster scholarship. Rather, they should be conceptualized in ways that enrich vulnerability 
perspectives without creating unnecessary conceptual inconsistency.

Famines, as one example of how creeping disasters produce distinct dynamics, demand that we allow for such nuances and temporal perspectives not only in root cause analyses but also in how impacts are experienced and managed. The lived experience of famine disasters is temporally stretched and so are necessarily responses to famine. Among other things, the very existence of such disasters is more likely to be contested as unaffected groups may organize to deny the reality of a slowly developing creeping disaster, such as a famine (elites often have incentives for denying the existence of an emerging famine). This does not make them any less a product of a long range of root causes, proving logically that discussions of disaster onset patterns are by no means antithetical to considerations of vulnerability in disaster research. Increased attention to aspects of onset could provide novel theoretical insights as well as valuable practical lessons for disaster researchers, policy makers, and practitioners.

Creeping disasters, importantly, should not be approached as representing entirely novel challenges, although some aspects are distinct. An important implication of this article is that the notion of onset needs further theorization and empirical clarification in disaster research. A more fruitful approach is to understand creeping disasters as a category of disasters that exhibits certain key characteristics to a greater extent than other types of disasters. This perspective does not demand a definition of creeping disasters that is conceptually distinct from that of disasters as we commonly understand the concept. The distinction is not based on a binary understanding of mutually excluding categories but rather on a continuum of different characteristics that make it possible to classify disasters that exhibit stretched temporal manifestation dynamics as presenting a set of distinct challenges for disaster risk science.

Acknowledgements This work was funded by the European Union's Horizon 2020 research and innovation program under the Marie Skłodowska-Curie Grant Agreement No. 897656.

Open Access This article is licensed under a Creative Commons Attribution 4.0 International License, which permits use, sharing, adaptation, distribution and reproduction in any medium or format, as long as you give appropriate credit to the original author(s) and the source, provide a link to the Creative Commons licence, and indicate if changes were made. The images or other third party material in this article are included in the article's Creative Commons licence, unless indicated otherwise in a credit line to the material. If material is not included in the article's Creative Commons licence and your intended use is not permitted by statutory regulation or exceeds the permitted use, you will need to obtain permission directly from the copyright holder. To view a copy of this licence, visit http://creativecommons. org/licenses/by/4.0/.

\section{References}

Ahrens, W. 2003. Cultural and political obstacles to accepting early warnings of the Aral Sea disaster. In Early warning systems for natural disaster reduction, ed. J. Zschau, and A. Küppers, 305-310. Berlin: Springer.

Alcántara-Ayala, I., and A. Oliver-Smith. 2015. The necessity of Early Warning Articulated Systems (EWASs): Critical issues beyond response. In Identifying emerging issues in disaster risk reduction, migration, climate change and sustainable development, ed. K. Sudmeier-Rieux, M. Fernández, I. Penna, M. Jaboyedoff, and J. Gaillard, 101-124. Cham: Springer.

Birkland, T.A. 1998. Focusing events, mobilization, and agenda setting. Journal of Public Policy 18(1): 53-74.

Boin, A., M. Ekengren, and M. Rhinard. 2020. Hiding in plain sight: Conceptualizing the creeping crisis. Risk, Hazards \&amp; Crisis in Public Policy 11(2): 116-138.

Boin, A., and P. 't Hart, E. Stern, and B. Sundelius. 2017. The politics of crisis management: Public leadership under pressure, 2nd edn. Cambridge: Cambridge University Press.

Bosher, L., K. Chmutina, and D. van Niekerk. 2021. Stop going around in circles: Towards a reconceptualisation of disaster risk management phases. Disaster Prevention and Management 30(4/ 5): 525-537.

Burton, I., R.W. Kates, and G.F. White. 1993. The environment as hazard, 2nd edn. New York: Guilford Press.

Coetzee, C., and D. van Niekerk. 2012. Tracking the evolution of the disaster management cycle: A general system theory approach. Jàmbá: Journal of Disaster Risk Studies 4(1): 1-9.

Conley, B., and A. de Waal. 2019. The purposes of starvation: Historical and contemporary uses. Journal of International Criminal Justice 17(4): 699-722.

Costella, C., C. Jaime, J. Arrighi, E.C. de Prez, P. Suarez, and M. van Aalst. 2017. Scalable and sustainable: How to build anticipatory capacity into social protection systems. IDS Bulletin: Transforming Development Knowledge 48(4): 31-46.

DeFalco, R. 2017. Conceptualizing famine as a subject of international criminal justice: Towards a modality-based approach. University of Pennsylvania Journal of International Law 38(1): 1113-1187.

DeLeo, R.A. 2016. Anticipatory policymaking: When government acts to prevent problems and why it is so difficult. London: Routledge.

De Waal, A. 1989. Famine mortality: A case study of Darfur, Sudan 1984-85. Population Studies 43(1): 5-24.

De Waal, A. 1993. War and famine in Africa. IDS Bulletin: Transforming Development Knowledge 24(4): 33-40.

De Waal, A. 1997. Famine crimes. London: Villiers Publications.

De Waal, A. 2018. Mass starvation: The history and future of famine. Cambridge: Polity Press.

Devereux, S. 2007. The new famines: Why famines persist in an era of globalization. London: Routledge.

Dowlah, C. 2006. The politics and economics of food and famine in Bangladesh in the early 1970 s-with special reference to Amartya Sen's interpretation of the 1974 famine. International Journal of Social Welfare 15(4): 344-356.

Dynes, R.R. 2004. Expanding the horizons of disaster research. Natural Hazards Observer 28(4): 1-2.

Fergusson, J. 2013. The world's most dangerous place: Inside the outlaw state of Somalia. London: Black Swan Publishing.

Fritz, C.E. 1961. Disaster. In Contemporary social problems, ed. R.K. Merton, and R. Nisbet, 651-694. New York: Harcourt, Brace \& World.

Glantz, M.H. 1976. The politics of natural disasters: The case of the Sahel drought. New York: Praeger. 
Glantz, M.H. 1994. Creeping environmental problems. The World and I 1994: 218-225.

Gráda, C.Ó. 2009. Famine: A short history. Princeton: Princeton University Press.

Hannigan, J. 2013. Disasters without borders: The international politics of natural disasters. Cambridge: Polity Press.

Healy, A., and N. Malhotra. 2009. Myopic voters and natural disaster policy. American Political Science Review 103(3): 387-406.

Heaton, L. 2012. Somalia famine relief: A view from Mogadishu. Washington, DC: The Enough Project.

Hewitt, K. 1983. The idea of calamity in a technocratic age. In Interpretations of calamity: From the viewpoint of human ecology, ed. K. Hewitt, 3-32. Boston: Allen \& Unwin.

Hewitt, K. 1995. Sustainable disasters? Perspectives and power in the discourse of calamity. In Power of development, ed. J. Crash, 115-128. London: Routledge.

Howe, P. 2018. Famine systems: A new model for understanding the development of famines. World Development 105(C): 144-155.

Howe, P., and S. Devereux. 2004. Famine intensity and magnitude scales: A proposal for an instrumental definition of famine. Disasters 28(4): 353-372.

Hsu, E.L. 2019. Must disasters be rapidly occurring? The case for an expanded temporal typology of disasters. Time \& Society 28(3): Article 904921.

IFRC (International Federation of Red Cross and Red Crescent Societies). 2020. What is a disaster? https://www.ifrc.org/en/ what-we-do/disaster-management/about-disasters/what-is-a-dis aster/. Accessed 28 Jul 2021.

IPC (Integrated Food Security Phase Classification). 2020. IPC resource 01: Famine classification. Rome: Integrated Food Security Phase Classification (IPC).

IPC (Integrated Food Security Phase Classification). 2021. Famine review of the IPC acute food insecurity analysis. Rome: Integrated Food Security Phase Classification (IPC).

Jaime, H. 2013. The "silent disaster" of local losses. UNISDR working paper prepared for the Global Assessment Report on Disaster Risk Reduction (GAR) 2013. Geneva: UNISDR.

Keen, D. 1993. Famine, needs-assessment and survival strategies in Africa. Oxfam Research Papers 8. Oxford: Oxfam GB.

Keen, D. 1994. The benefits of famine. Princeton: Princeton University Press.

Kelman, I. 2019. Pacific island regional preparedness for El Niño. Environment, Development and Sustainability 21(1): 405-428.

Kelman, I. 2020. Disaster by choice. Oxford: Oxford University Press.

Kelman, I., and M.H. Glantz. 2014. Early warning systems defined. In Reducing disaster: Early warning systems for climate change, ed. S. Singh, and Z. Zommers, 89-108. Dordrecht: Springer.

Kelman, I., J. Field, K. Suri, and G.M. Bhat. 2018. Disaster diplomacy in Jammu and Kashmir. International Journal for Disaster Risk Reduction 31: 1132-1170.

Kruke, B.I., and O.E. Olsen. 2012. Knowledge creation and reliable decision-making in complex emergencies. Disasters 36(2): 212-232.

Lautze, S., W. Bell, L. Alinovi, and L. Russo. 2012. Early warning, late response (again): The 2011 famine in Somalia. Global Food Security 1(1): 43-49.

Lewis, J. 1988. On the line: An open letter in response to "Confronting natural disasters, an international decade for natural hazard reduction". Natural Hazards Observer 7(4): Article 4

Marcus, D. 2003. Famine crimes in international law. The American Journal of International Law 97(2): 245-281.

Marulanda, M.C., O.D. Cardona, and A.H. Barbat. 2010. Revealing the socioeconomic impact of small disasters in Colombia using the DesInventar Database. Disasters 34(2): 552-570.
Matthewman, S. 2015. Disasters, risk and revelation: Making sense of our times. Basingstoke, UK: Palgrave Macmillan.

Maxwell, D., and M. Fitzpatrick. 2012. The 2011 Somalia famine: Context, causes and complications. Global Food Security 1(1): $5-12$.

Maxwell, D., A. Khalif, P. Hailey, and F. Checchi. 2020. Determining famine: Multi-dimensional analysis for the twenty-first century. Food Policy 92: Article 101832.

Meriläinen, E., and M. Koro. 2021. Data, disasters, and space-time entanglements. International Journal of Disaster Risk Science 12(1): $157-168$.

Neal, D.M. 1997. Reconsidering the phases of disasters. International Journal of Mass Emergencies and Disasters 15(2): 239-264.

OCHA (United Nations Office for the Coordination of Humanitarian Affairs). 2011. OCHA and slow-onset emergencies. OCHA Occasional Policy Briefing Series 6. New York: OCHA.

OHCHR (Office of the United Nations High Commissioner for Human Rights). 2021. Special rapporteur on the right to food. https://www.ohchr.org/en/issues/food/pages/foodindex.aspx. Accessed 28 Jul 2021.

Osmani, S.R. 1993. The entitlement approach to famine: An assessment. WIDER Working Papers 107. Helsinki: United Nations University / World Institute for Development Economics Research (UNU/WIDER).

Patnaik, U. 1991. Food availability and famine-A longer view. Journal of Peasant Studies 19(1): 1-25.

Perry, R.W., and E.L. Quarantelli. 2005. What is a disaster? New answers to old questions. Philadelphia: Xlibris.

Quarantelli, E.L. 1991. Disaster research: An entry for an encyclopedia. Preliminary Papers 167. Newark, DE: University of Delaware Disaster Research Center.

Quarantelli, E.L. 1997. Ten criteria for evaluating the management of community disasters. Disasters 21(1): 39-56.

Quarantelli, E.L. 1998. What is a disaster? Perspectives on the question. London: Routledge.

Quarantelli, E.L. 2000. Emergencies, disasters and catastrophes are different phenomena. Preliminary Papers 304. Newark, DE: University of Delaware Disaster Research Center.

Rosenthal, U. 1998. Future disasters, future definitions. In What is a disaster? Perspectives on the question, ed. E.L. Quarantelli, 146-159. London: Routledge.

Rubin, O. 2009. The entitlement approach: A case for framework development rather than demolition: A comment on "Entitlement failure and deprivation: A critique of Sen's famine philosophy". The Journal of Development Studies 45(4): 621-640.

Rubin, O. 2009. The merits of democracy in famine protection - Fact or fallacy?. The European Journal of Development Research 21: 699-717.

Rubin, O. 2018. The political dynamics of voter retrospection and disaster responses. Disasters 44(2): 239-261.

Rubin, O. 2019. The precarious state of famine research. The Journal of Development Studies 55(8): 1633-1653.

Seaman, J. 1993. Famine mortality in Africa. IDS Bulletin: Transforming Development Knowledge 24(4): 27-32.

Sen, A. 1981. Poverty and famines. Oxford: Oxford University Press.

Sen, A. 1999. Development as freedom. New York: Knopf.

Shaluf, I.M. 2007. An overview on disasters. Disaster Prevention and Management 16(5): 687-703.

Staupe-Delgado, R. 2019a. Progress, traditions and future directions in research on disasters involving slow-onset hazards. Disaster Prevention and Management 28(5): 623-635.

Staupe-Delgado, R. 2019b. Overcoming barriers to proactive response in slow-onset disasters. Contributing Paper to GAR 2019. Geneva: UNDRR. 
Staupe-Delgado, R. 2022. Disasters and life in anticipation of slow calamity: Perspectives from the Colombian Andes. Abingdon: Routledge.

Staupe-Delgado, R., B.I. Kruke, R.J. Ross, and M.H. Glantz. 2018. Preparedness for slow-onset environmental disasters: Drawing lessons from three decades of El Niño impacts. Sustainable Development 26(6): 553-563.

Tierney, K., and M. Bruneau. 2007. Conceptualizing and measuring resilience: A key to disaster loss reduction. TR News 250 (MayJune): 14-17.

Twigg, J. 2004. Disaster risk reduction: Mitigation and preparedness in development and emergency programming. London: Humanitarian Practice Network (HPN), Overseas Development Institute (ODI).

UNDRR (United Nations Office for Disaster Risk Reduction). 2017. Terminology. https://www.preventionweb.net/terminology/view/ 475. Accessed 28 Jul 2021.

Viens, A.M., and J. Littmann. 2015. Is antimicrobial resistance a slowly emerging disaster?. Public Health Ethics 8(3): 255-265.
WFP (United Nations World Food Programme). 2021. WFP warns of countdown to catastrophe as acute hunger reaches new peak. https://www.wfp.org/news/wfp-warns-countdown-catastropheacute-hunger-reaches-new-peak. Accessed 8 Dec 2021.

Wilhite, D.A., and M.H. Glantz. 1985. Understanding: The drought phenomenon: The role of definitions. Water International 10(3): 111-120.

Wisner, B., P. Blaikie, T. Cannon, and I. Davis. 2004. At risk: Natural hazards, people's vulnerability and disasters, 2nd edn. London: Routledge.

Yamori, K., and J.D. Goltz. 2021. Disasters without borders: The coronavirus pandemic, global climate change and the ascendancy of gradual onset disasters. International Journal of Environmental Research and Public Health 18(6): Article 3299.

Zaidi, R.Z. 2018. Beyond the Sendai indicators: Application of a cascading risk lens for the improvement of loss data indicators for slow-onset hazards and small-scale disasters. International Journal of Disaster Risk Reduction 30: 306-314. 